\title{
Uremic encephalopathy in critical care: does it exist and does renal replacement therapy improve outcome?
}

\author{
M de Mos $^{1 *}$, EJ Hoorn², D Dippel ${ }^{3}$, J van Bommel ${ }^{4}$ \\ From ESICM LIVES 2015 \\ Berlin, Germany. 3-7 October 2015
}

\begin{abstract}
Introduction
Neurological disturbances and acute kidney injury (AKI) commonly co-exist in critically ill patients. However, it is unclear if AKI directly contributes to neurological disturbances (uremic encephalopathy) or if neurological disturbances and AKI are both reflections of multiorgan failure. Furthermore, it is unclear if renal replacement therapy (RRT) improves outcome, especially if other indications for RRT are absent.
\end{abstract}

\section{Objectives}

To analyze the incidence, characteristics, effect of RRT, and outcomes in patients with neurological disturbances and AKI.

\section{Methods}

During the study-period 2012-2013 at an university hospital intensive care unit (ICU) in The Netherlands, we retrospectively reviewed all neurology consults $(n=803)$ and then selected patients with concomitant AKI. Patients with intracranial pathology were excluded. After detailed analysis by a neurologist and nephrologist, patients were classified as neurological disturbances with AKI (NWH, neurological status attributable to several causes, including AKI) or neurological disturbances due to AKI (NDA, no other explanation for the neurological status than AKI).

\section{Results}

The incidence of neurological disturbances and AKI was 6.6 per 1,000 ICU admissions (95\% CI $4.7-9.1$ ). Of the 35 patients with neurological disturbances and AKI, NWA was four times more common than NDA (28 vs. 7

${ }^{1}$ Erasmus MC University Medical Center, Anesthesiology, Rotterdam, the Netherlands

Full list of author information is available at the end of the article patients). Patients with NDA were more uremic (serum urea 42 vs. $23 \mathrm{mmol} / \mathrm{l}, \mathrm{p}=0.005)$, but had lower sequential organ failure (SOFA) scores (11.6 vs. 13.8, $\mathrm{p}=0.04)$. RRT was started in $71 \%$ of NDA cases (in two patients coma was the only indication) and in $46 \%$ of NWA cases $(\mathrm{p}=0.2)$. 28-day mortality was $57 \%$ in the NDA cases and $82 \%$ in the NWA cases $(\mathrm{p}=0.2)$. Patients receiving RRT did not have better outcomes than patients not receiving RRT (neurological improvement 33 vs. 41\%; 28day mortality 83 vs. $69 \%$; $>0.05$ for both).

\section{Conclusions}

In critically ill patients with neurological disturbances and AKI, AKI is usually only one of the possible factors contributing to the neurological status. The combination of AKI and neurological disturbances signals a poor prognosis with RRT having little effect on neurological improvement or mortality.

\section{Authors' details}

${ }^{1}$ Erasmus MC University Medical Center, Anesthesiology, Rotterdam, the Netherlands. '2Erasmus MC University Medical Center, Nephrology, Rotterdam, the Netherlands. ${ }^{3}$ Erasmus MC University Medical Center, Neurology, Rotterdam, the Netherlands. ${ }^{4}$ Erasmus MC University Medical Center, Intensive Care, Rotterdam, the Netherlands.

Published: 1 October 2015

References

1. Weathers AL, Lewis SL: Rare and Unusual ... Or Are They? Less Commonly Diagnosed Encephalopathies Associated with Systemic Disease. Semin Neurol 2009, 29(2):136-153.

2. Frontera JA: Metabolic encephalopathies in the critical care unit. Continuum (Minneap Minn) 2012, 18(3):611-639.

doi:10.1186/2197-425X-3-S1-A468

Cite this article as: de Mos et al:: Uremic encephalopathy in critical care: does it exist and does renal replacement therapy improve outcome? Intensive Care Medicine Experimental 2015 3(Suppl 1):A468.

\section{SpringerOpen ${ }^{\odot}$}

C 2015 de Mos et al.; This is an Open Access article distributed under the terms of the Creative Commons Attribution License (http:// creativecommons.org/licenses/by/4.0), which permits unrestricted use, distribution, and reproduction in any medium, provided the original work is properly cited. 